\title{
Approach to Emergent Neurotrauma-related Neurosurgical Procedures in Patients with Hepatic Disease
}

\author{
María Mendoza-Avendaño ${ }^{1}$ Ana Ramírez-Carvajal ${ }^{1}$ Iván Barreto-Herrera ${ }^{1}$ \\ Karen Muñoz-Báez ${ }^{1}$ Yancarlos Ramos-Villegas ${ }^{1}$ Adesh Shrivastava ${ }^{2}$ Tariq Janjua ${ }^{3}$ \\ Luis Rafael Moscote-Salazar ${ }^{1} \quad$ Amit Agrawal $^{2}$
}

${ }^{1}$ Faculty of Medicine, Center for Biomedical Research, University of

Address for correspondence Amit Agrawal, MCh, Department of Cartagena, Cartagena, Colombia

${ }^{2}$ Department of Neurosurgery, All India Institute of Medical

Sciences, Bhopal, Madhya Pradesh, India

3 Intensive Care Department, Regions Hospital, Saint Paul,

Minnesota, United States

Indian J Neurotrauma 2021;18:133-137.

Neurosurgery, All India Institute of Medical Sciences, Saket Nagar, Bhopal, Madhya Pradesh 462020, India

(e-mail: dramitagrawal@gmail.com).

\begin{abstract}
Keywords

- hepatopathies

- liver disease

- neurosurgery
\end{abstract}

\section{Introduction}

The global incidence of chronic liver diseases (CLDs) is on a steady rise. The pathology of CLDs is widespread, including viral hepatitis, alcoholic liver disease, and nonalcoholic hepatic steatosis. Advances in the treatment of liver pathologies has led to an increase in the survival of patients with CLDs and progression to advanced cirrhosis and even hepatocellular carcinoma. ${ }^{1}$ This creates a greater challenge for doctors, since the treatment of the presenting pathology is complicated by underlying liver diseases. ${ }^{2-6}$ This is true even for neurological disorders, especially neurotrauma cases that require emergency surgery. Hence, it becomes crucial to stratify the surgical risk in patients with liver diseases at the time of undergoing brain surgeries as well as the identification of preoperatively modifiable risk factors. This is essential to address and optimize the patients to reduce perioperative complications and improve postoperative results. This article attempts to present an updated review on the current understanding and approach for treating CLD patients presenting with neurotrauma. published online February 23, 2021
DOI https://doi.org/

10.1055/s-0041-1725215 ISSN 0973-0508. (c) 2021. Neurotrauma Society of India.

This is an open access article published by Thieme under the terms of the Creative Commons Attribution-NonDerivative-NonCommercial-License, permitting copying and reproduction so long as the original work is given appropriate credit. Contents may not be used for commercial purposes, or adapted, remixed, transformed or built upon. (https://creativecommons.org/licenses/by-nc-nd/4.0/).

Thieme Medical and Scientific Publishers Pvt. Ltd. A-12, 2nd Floor, Sector 2, Noida-201301 UP, India 


\section{Overview}

The adverse association between CLDs and surgery is clearly pronounced in literature, and liver cirrhosis has even been extensively described as a risk factor associated with increased morbidity and mortality. ${ }^{7-9}$ The morbidity rate in patients with liver cirrhosis has been reported in literature to be $52.1 \%$ with mortality rate of $24.3 \% .^{10,11}$ Studies established that the greater the severity of the liver disease, the greater the risk of mortality and the poorer prognosis with neurosurgeries. ${ }^{10,12}$ Severe liver disease itself complicates surgical procedures to a greater extent by various mechanisms including protein synthesis dysfunction which, in turn, leads to hypoproteinemia, difficulty in wound healing, and physical recovery from the procedure. ${ }^{13}$ Further, cirrhosis leads to portal hypertension that increases collateral circulations and hematological alterations of liver diseases such as deficiencies of coagulation factors, vitamin $\mathrm{K}$ and thrombocytopenia due to splenic sequestration that increase the risk of surgical bleeding. ${ }^{14,15}$

Preoperative Risk Factors in Patients with Liver Disease It has been described that the presence of underlying liver disease is associated with poor postoperative results. CLD in itself encompasses many important complications, such as hepatic encephalopathy and coagulopathies, ${ }^{16}$ which lead to significant impact on any type of surgery. Neurosurgical patients are especially vulnerable to adverse outcomes due to risk of intracranial hemorrhage. ${ }^{17}$ This makes it fundamentally important for surgeons to know which preoperative risk factors could lead to poor outcomes in patients with liver disease at the time of neurological surgery. ${ }^{11} \mathrm{~A}$ study performed in 2018 with a large cohort of patients described that patients undergoing neurosurgical interventions with liver disease have a higher risk of mortality and an increase in hospital stay of more than 10 days compared with those without liver disorders. ${ }^{18}$ For this reason, surgeons must be cautious when considering a patient with liver disease as a candidate for neurosurgery. As a major preoperative risk factor, CLD deranges the coagulation system and thus not only leads to spontaneous intracranial hemorrhage requiring surgical treatment ${ }^{19}$ but also increases the risk of rebleeding, reoperations, and transfusion of blood products. ${ }^{20}$

Another risk factor that impacts postoperative outcomes is the nutritional status of patients with liver disease, since they have low levels of albumin preoperatively, which negatively impacts the healing of cranial wounds and increases chances of infections with lethal complications..$^{21,22}$

Several independent risk factors with liver disease which increase the risk of devastating consequences in patients undergoing brain surgery include heart failure, kidney disease, stroke, and viral hepatitis as a cause of cirrhosis. ${ }^{23}$ For this reason, the identification and prompt correction of modifiable risk factors in patients with liver disease who require neurosurgical surgery become important to reduce the incidence of complications and improve postoperative outcomes.

\section{Scales to Evaluate Liver Fibrosis}

AST to Platelet Ratio Index (APRI index)

The APRI index indirectly evaluates the degree of fibrosis through the index between the level of the enzyme aspartate aminotransferase and the platelet counts. ${ }^{24}$ This has been recommended by the World Health Organization (WHO) to assess the degree of fibrosis in patients with hepatitis $C$ due to its ease of performance and cost. ${ }^{25}$

A meta-analysis performed in 2009 which compiled data from 22 studies established a sensitivity of $81 \%$ and a specificity of $50 \%$ for determining liver fibrosis by the APRI index. ${ }^{26}$ Likewise, a retrospective study performed in 2016, which included 798 patients with chronic hepatitis C, also established a sensitivity for this test at $81 \%$ with an APRI cutoff point $>2$ to define patients with cirrhosis. ${ }^{25}$ This sensitivity adds to the relationship that has been evident between the APRI score and the postsurgical outcome. This makes it useful at the time of the presurgical evaluation. ${ }^{18}$

$$
\begin{aligned}
& \text { APRI }=\frac{\text { AST/AST(upper limit of normal) }}{\text { Platelet counts }} \times 100 \\
< & 0.5 \text { rules out significant fibrosis } \\
> & 1.5 \text { rules in significant fibrosis } \\
> & 2.0 \text { cirrhosis }
\end{aligned}
$$

\section{Child-Turcotte-Pugh (CTP) Score}

This scale assesses the albumin level, bilirubin level, prothrombin time, international normalized ratio (INR), presence or absence of ascites and encephalopathy. ${ }^{27}$ According to the score obtained, the patients is classified in category $\mathrm{A}, \mathrm{B}$ or $\mathrm{C}$, giving a rate estimated mortality according to subgroups. Category A patients have a mortality rate between $5 \%$ and $10 \%$, category $B$ patients between $10 \%$ and $40 \%$, and category $C$ patients have a mortality rate of $20 \%$ to $100 \%$, and this variability is determined by the associated comorbidities. ${ }^{27,28}$

Chen et al $^{10}$ studied patients with liver cirrhosis who underwent brain surgery and concluded that patients with the progressive liver cirrhosis (based on the Child classification) who were undergoing brain surgery had poorer outcome. These studies allow neurosurgeons to have better guidance on decision-making when faced with a patient having concomitant liver disease. Based on the severity score, they will be able to calculate the risk of complications including mortality and determine the relevance of performing the procedure or not. ${ }^{18,27}$ 
Table 1 CTP score determining estimated mortality according to subgroups

\begin{tabular}{|l|l|l|l|}
\hline & $\mathbf{1}$ & $\mathbf{2}$ & $\mathbf{3}$ \\
\hline Encephalopathy & 0 & $1-2$ & $3-4$ \\
\hline Ascites & 0 & Mild & Major \\
\hline Bilirubin $(\mathrm{mg} / \mathrm{dl})$ & $<2$ & $2-3$ & $>3$ \\
\hline Albumin $(\mathrm{g} / \mathrm{dl})$ & $>3.5$ & $2.8-3.5$ & $<2.8$ \\
\hline PT prolonged $(\mathrm{s})$ & $1-4$ & $5-6$ & $>6$ \\
\hline INR & $<1.7$ & $1.8-2.3$ & $>2.3$ \\
\hline $\begin{array}{l}\text { Child's A = 5-6 } \\
\text { points }\end{array}$ & $\begin{array}{l}\text { Child's B = } \\
7-9 \text { points }\end{array}$ & $\begin{array}{l}\text { Child's } \\
\mathrm{C}=10-15 \text { points }\end{array}$ \\
\hline
\end{tabular}

Abbreviations: CTP, Child-Turcotte-Pugh; INR, international normalized ratio; PT, prothrombin time.

\section{Model of End-Stage Liver Disease (MELD)}

The score is obtained through the following biochemical tests: bilirubin, INR, and creatinine. The result is directly proportional to the risk of surgical complications, that is, the higher the score, the greater the risk (-Table 1). There is variability in the results of the studies performed to determine a cutoff point; however, it has been seen that values equal to or greater than 8 have a high postsurgical morbidity and mortality. ${ }^{28}$ In search of obtaining a more accurate score on the severity of liver disease and surgical risk, from 2016, after several studies, the MELD score included the serum sodium level in its tests, as hyponatremia has been established as a negative predictor in postoperative results in patients undergoing liver transplantation. ${ }^{29}$

\section{Evaluation of Preoperative Liver Disease}

The increase in the incidence of patients with liver disease has led to expanding the study of this pathology. Various scales have been created to assess the degree of liver injury, and determine the risk, complications and postsurgical prognosis..$^{18}$ Although liver biopsy is the gold standard for diagnosing liver impairment, it is an invasive test, different clinical and laboratory parameters have been sought which more accurately approximate the severity of the disease. ${ }^{24,30}$ These scales, in addition to being inexpensive and easy to perform, must have a high sensitivity to identify patients with cirrhosis either to rule out any surgical intervention including elective ones or, if possible, to control risk factors as evidenced by high morbidity and mortality. ${ }^{27}$

\section{Complications and Postsurgical Outcome in Patient with Liver Disease}

Postsurgical complications in the cirrhotic patient are related to the extent of liver injury, comorbidities, type of surgical procedure, and medical expertise. Out of these factors, the degree of dysfunction of liver disease appears to be the factor with the greatest impact on risk of mortality. ${ }^{27}$ In the neurosurgical setting, a life-threatening complication is intracranial hemorrhage. However, it is sometimes can be overlooked due to the clinical similarities of neurologic deficits, which can be caused by hepatic encephalopathy. The evacuation of these hematomas represents $30.6 \%$ of neurosurgical procedures in patients with cirrhosis. ${ }^{11,12,19}$

Additionally, complications related to cirrhosis may be associated with acquired hemostatic deficiency, since coagulopathy can impair the hemostasis in these patients, with resultant increase in morbidity and mortality. Faced with incompetent hemostasis, the need for transfusion is the most anticipated complication. ${ }^{10,18,19,31-33}$ Liao et al ${ }^{34}$ reported greater blood loss and prolonged hospital stay in patients who underwent lumbar instrumentation and had liver cirrhosis. Similarly, another study by Goel et al, which included patients undergoing craniotomy for brain tumor, showed that liver disease is a significant predictor of surgical morbidity and mortality, with increased hospital stay due to multiple causes such as coagulopathy, hepatic encephalopathy, pulmonary failure, poor wound healing, and immunocompromise. ${ }^{18}$ This demonstrates the importance of knowing the relationship between liver disease and risk of spontaneous intracranial hemorrhage while planning neurosurgical internventions. ${ }^{17-19,34-37}$

Because the complications of neurosurgical procedures in patients with liver cirrhosis are caused by alterations in coagulation, transfusion of fresh frozen plasma (FFP) has been suggested. Additionally, administration of vitamin $\mathrm{K}$ to correct the value of prothrombin time as well as maintaining a platelet level $>50,000$ are recommended. ${ }^{38-40}$ An uncontrollable variable that has an impact on the results of patients with liver cirrhosis is the urgency with which surgical procedures are required regardless of the type, since emergency surgery always carries a greater risk of morbidity and mortality. In these patients the risk can be two times higher than in the general population. ${ }^{27}$ It has been suggested to improve the CTP score before surgical intervention in the cirrhotic patient to reduce the impact on morbidity and mortality. However, this optimization of liver function is not entirely practical, considering that neurosurgical interventions for bleeding intracranial is mostly an emergent management. ${ }^{12}$

\section{Conclusions}

Advances in medicine for the management of patients with liver disease have brought with them new challenges for surgeons, due to the increase in the requirement for surgical procedures. This raises questions about which patients should undergo surgery and which patients should not, and how to measure severity of liver disease and how to reduce postsurgical risks. Little is known about neurosurgical procedures, and there is no consensus on the most accurate scale for evaluating the severity of liver disease and thus surgical risk in neurosurgical patients. This is of vital importance in emergency settings where adequate optimization may not be a choice. The frequently used CTP and MELD scores, which determine the risk of morbidity and mortality, aid in decision-making regarding risks associated with a surgical procedure. This risk must be taken based on the calculated risk-benefit ratio and adequate 
patient information. It is necessary to control the possible complications of these patients, as well as the surgical risk, through the management of ascites, nutritional support, maintenance of albumin levels and, in case of bleeding, FFP transfusions and administration of vitamin $\mathrm{K}$.

\section{Conflict of Interest}

None declared.

\section{References}

1 Mokdad AA, Lopez AD, Shahraz S, et al. Liver cirrhosis mortality in 187 countries between 1980 and 2010: a systematic analysis. BMC Med 2014;12:145

2 Cramer JD, Patel UA, Samant S, Yang A, Smith SS. Liver disease in patients undergoing head and neck surgery: Incidence and risk for postoperative complications. Laryngoscope 2017;127(1):102-109

3 Dangleben DA, Jazaeri O, Wasser T, Cipolle M, Pasquale M. Impact of cirrhosis on outcomes in trauma. J Am Coll Surg 2006;203(6):908-913

4 Ferreira PP, Camara EJ, Paula RL, Zollinger CC, Cavalcanti AR, Bittencourt PL. Prevalence of hepatopulmonary syndrome in patients with decompensated chronic liver disease and its impact on short-term survival. Arq Gastroenterol 2008;45(1):34-37

5 Makowiec F, Mariaskin D, Spangenberg H, Hopt UT. Perioperative mortality after nonhepatic general surgery in patients with concomitant liver cirrhosis: an analysis of 138 operations in the 2000s using Child and MELD Scores. Gastroenterology 2009;15(1):1-11

6 Nyberg EM, Batech M, Cheetham TC, et al. Postoperative Risk of Hepatic Decompensation after Orthopedic Surgery in Patients with Cirrhosis. J Clin Transl Hepatol 2016;4(2):83-89

7 Marrocco-Trischitta MM, Kahlberg A, Astore D, Tshiombo G, Mascia D, Chiesa R. Outcome in cirrhotic patients after elective surgical repair of infrarenal aortic aneurysm. J Vasc Surg 2011;53(4):906-911

8 Talving P, Lustenberger T, Okoye OT, et al. The impact of liver cirrhosis on outcomes in trauma patients: a prospective study. J Trauma Acute Care Surg 2013;75(4):699-703

9 Thielmann M, Mechmet A, Neuhäuser M, et al. Risk prediction and outcomes in patients with liver cirrhosis undergoing open-heart surgery. Eur J Cardiothorac Surg 2010;38(5):592-599

10 Chen CC, Hsu PW, Lee ST, et al. Brain surgery in patients with liver cirrhosis. J Neurosurg 2012;117(2):348-353

11 Chen C-C, Huang Y-C, Yeh C-N. Neurosurgical procedures in patients with liver cirrhosis: A review. World J Hepatol 2015;7(21):2352-2357

12 Lagman C, Nagasawa DT, Sheppard JP, et al. End-stage liver disease in patients with intracranial hemorrhage is associated with increased mortality: a cohort study. World Neurosurg 2018;113:e320-e327

13 Johnson TM, Overgard EB, Cohen AE, DiBaise JK. Nutrition assessment and management in advanced liver disease. Nutr Clin Pract 2013;28(1):15-29

14 Garcia-Tsao G, Abraldes JG, Berzigotti A, Bosch J. Portal hypertensive bleeding in cirrhosis: Risk stratification, diagnosis, and management: 2016 practice guidance by the American Association for the study of liver diseases. Hepatology 2017;65(1):310-335

15 Tripodi A, Mannucci PM. The coagulopathy of chronic liver disease. N Engl J Med 2011;365(2):147-156
16 Friedman LS. Surgery in the patient with liver disease. Trans Am Clin Climatol Assoc 2010;121:192-204, discussion 205

17 Lai $\mathrm{CH}$, Cheng PY, Chen YY. Liver cirrhosis and risk of intracerebral hemorrhage: a 9-year follow-up study. Stroke 2011;42(9):2615-2617

18 Goel NJ, Abdullah KG, Choudhri OA, Kung DK, Lucas TH, Chen HI. The Effect of Underlying Liver Disease on Perioperative Outcomes Following Craniotomy for Tumor: An American College of Surgeons National Quality Improvement Program Analysis. World Neurosurg 2018;115:e85-e96

19 Huang $\mathrm{HH}$, Lin $\mathrm{HH}$, Shih YL, et al. Spontaneous intracranial hemorrhage in cirrhotic patients. Clin Neurol Neurosurg 2008;110(3):253-258

20 Degos V, Westbroek EM, Lawton MT. Hemphill JC III, Del Zoppo GJ, Young WL. Perioperative management of coagulation in nontraumatic intracerebral hemorrhage. Anesthesiology 2013;119(1):218-227

21 Kao HK, Chen WF, Chen CH, Shyu VB, Cheng MH, Chang KP. The roles of albumin levels in head and neck cancer patients with liver cirrhosis undergoing tumor ablation and microsurgical free tissue transfer. PLoS One 2012;7(12):e52678

22 Ray AC, Philandrianos C, Bertrand B, et al. Two-stage free flap reconstruction of the scalp and calvaria for large neurosurgical resections. Microsurgery 2020;40(3):331-336

23 Cheng C-Y, Ho C-H, Wang C-C, et al. One-year mortality after traumatic brain injury in liver cirrhosis patients-A ten-year population-based study. Medicine (Baltimore) 2015;94(40):e1468-e1468

24 Loaeza-del-Castillo A, Paz-Pineda F, Oviedo-Cárdenas E, Sánchez-Avila F, Vargas-Vorácková F. AST to platelet ratio index (APRI) for the noninvasive evaluation of liver fibrosis. Ann Hepatol 2008;7(4):350-357

25 de Oliveira AC, El-Bacha I, Vianna MV, Parise ER. Utility and limitations of APRI and FIB4 to predict staging in a cohort of nonselected outpatients with hepatitis C. Ann Hepatol 2016;15(3):326-332

26 Shaheen AA, Myers RP. Diagnostic accuracy of the aspartate aminotransferase-to-platelet ratio index for the prediction of hepatitis C-related fibrosis: a systematic review. Hepatology 2007;46(3):912-921

27 Northup PG, Friedman LS, Kamath PS. AGA clinical practice update on surgical risk assessment and perioperative management in cirrhosis: expert review. Clin Gastroenterol Hepatol 2019;17(4):595-606

28 Newman KL, Johnson KM, Cornia PB, Wu P, Itani K, Ioannou GN. Perioperative evaluation and management of patients with cirrhosis: risk assessment, surgical outcomes, and future directions. Clin Gastroenterol Hepatol 2020;18(11):2398-2414

29 Godfrey EL, Kueht ML, Rana A, Awad S. MELD-Na (the new MELD) and peri-operative outcomes in emergency surgery. Am J Surg 2018;216(3):407-413

30 Manning DS, Afdhal NH. Diagnosis and quantitation of fibrosis. Gastroenterology 2008;134(6):1670-1681

31 Ferro D, Celestini A, Violi F. Hyperfibrinolysis in liver disease. Clin Liver Dis 2009;13(1):21-31

32 Kujovich JL. Hemostatic defects in end stage liver disease. Crit Care Clin 2005;21(3):563-587

33 Lin Y-T, Cheng Y-K, Lin C-L, Wang I-K. Increased risk of subdural hematoma in patients with liver cirrhosis. QJM 2017;110(12):815-820

34 Liao JC, Chen WJ, Chen LH, et al. Complications associated with instrumented lumbar surgery in patients with liver cirrhosis: a matched cohort analysis. Spine J 2013;13(8):908-913

35 Boudouresques G, Hauw JJ, Meininger V, et al. Hepatic cirrhosis and intracranial hemorrhage: significance of the association in 53 pathological cases. Ann Neurol 1980;8(2):204-205 
36 Grønbaek H, Johnsen SP, Jepsen P, et al. Liver cirrhosis, other liver diseases, and risk of hospitalisation for intracerebral haemorrhage: a Danish population-based case-control study. BMC Gastroenterol 2008;8:16-16

37 Parikh NS, Navi BB, Kumar S, Kamel H. Association between Liver Disease and Intracranial Hemorrhage. J Stroke Cerebrovasc Dis 2016;25(3):543-548

38 Dickneite G, Pragst I. Prothrombin complex concentrate vs fresh frozen plasma for reversal of dilutional coagulopathy in a porcine trauma model. Br J Anaesth 2009;102(3):345-354
39 Sarode R, Milling TJ Jr, Refaai MA, et al. Efficacy and safety of a 4-factor prothrombin complex concentrate in patients on vitamin $\mathrm{K}$ antagonists presenting with major bleeding: a randomized, plasma-controlled, phase IIIb study. Circulation 2013;128(11):1234-1243

40 Youssef WI, Salazar F, Dasarathy S, Beddow T, Mullen KD. Role of fresh frozen plasma infusion in correction of coagulopathy of chronic liver disease: a dual phase study. Am J Gastroenterol 2003;98(6):1391-1394 